\title{
ENSAIO SOBRE O MODELO PRODUTIVO FRANCÊS (O PARAdigma PRodutivo Pós-Fordista: ACOMOdaÇão OU RUPTURa COM O FORDISMO) $)^{*}$
}

\author{
Filipe Almeida Santos ${ }^{* *}$
}

\section{INTRODUÇÃO}

Ao longo deste ensaio, procurar-se-á entender todo o processo, por vezes contraditório, incerto e difícil, de emergência de um novo sistema produtivo no âmbito de uma realidade concreta. É da natureza de qualquer sistema produtivo criar e manter complementaridades entre a organização interna das empresas, as formas da concorrência, a natureza das relações industriais, o sistema educativo, sem esquecer a dinâmica macroeconómica. Desta definição realça-se que todo o sistema produtivo, que atinja a estabilidade estrutural, se torna incompatível com as formas de coordenação próprias do antigo sistema e bloqueia as inovações portadoras de um sistema superior. Compreende-se assim que, ao longo da história francesa, diversas configurações do sistema produtivo se tenham sucedido desde a primeira revolução industrial. A variação da envolvente económica nacional e internacional não é só por si susceptível de explicar a passagem de um sistema para outro, mas também a própria dinâmica impulsionada pelo paradigma produtivo faz emergir tendências que, a longo prazo, desestabilizam o próprio paradigma (Boyer, 1993a: 33).

Ninguém contesta que, desde os anos setenta, se operou e desenvolveu, ao longo de várias décadas, uma mudança profunda que mais não fez do que confirmar a crise do modelo de organização produtiva fordista e a superioridade de um novo modelo produtivo - o pós-fordismo. Todavia, este novo paradigma produ-

\footnotetext{
** Instituto Universitário de Desenvolvimento e Promoção Social - Pólo de Viseu da Universidade Católica Portuguesa.
} 
tivo está longe de ser considerado como sendo um sistema único e óptimo do tipo "one best way", apesar de ser corrente supor-se que o modelo de organização japonês acabará por se impor a prazo. Este prognóstico é deveras duvidoso, pelo facto de ignorar a complexidade dos procedimentos de coordenação necessários ao estabelecimento de um sistema produtivo, devendo-se ter em consideração as tradições nacionais, a configuração do sistema educativo, o papel do Estado, sem esquecermos o contexto internacional e o modo de regulação em vigor. Cada um dos sistemas produtivos, quer ele seja alemão, sueco ou japonês, tem as suas forças ou fraquezas, que são mais ou menos activadas consoante a conjuntura e o tipo de evolução macroeconómica. Nestas condições, trajectórias contrastantes podem coexistir, como, também, diversas e diferentes organizações podem garantir a competitividade, a longo prazo, do sistema produtivo correspondente.

Contudo, em França, apesar de ser lógico que o modelo que sucede ao fordismo se designe de pós-fordismo, nada garante que este último esteja em ruptura com o primeiro (cf. Durand, 1993a: 126). Este é porventura outro objectivo deste ensaio, ao pretendermos indagar se o sistema produtivo pós-fordista francês, vigente nos anos noventa, se encontra em ruptura com o modelo anterior, ou se, por sua vez, este novo modelo, que desponta numa época de crise do modelo fordista, não passa apenas de uma mera acomodação do modelo antecedente.

\section{O DESPONTAR E A EVOLUÇÃO DO MODELO PRODUTIVO FORDISTA FRANCÊS}

Por definição, um modelo produtivo organiza, num conjunto coerente, os princípios de gestão, a articulação com as empresas subcontratadas e a concorrência, para além das modalidades de gestão das relações salariais. Segundo Robert Boyer (1993a: 34), e relativamente ao modelo produtivo," le concept n'est pas purement micro-économique puisqu'il organise les interdependances entre la stratégie des firmes, le système de relations professionnelles et même la régulation macro-económique, de sorte que c'est un concept intermédiaire, méso-economique, dont l'intérêt est de permettre un passage du niveau de la firme à la dynamique et vice versa". Contrariamente, na corrente neoclássica reconhece-se que as variáveis reguladoras do sistema económico e de âmbito macroeconómico podem influenciar os princípios microeconómicos da organização produtiva das economias modernas, isto é, procura-se não efectuar uma análise do foro da organização industrial, mas também ter em consideração os modos de regulação, as determinantes macroeconómicas que determinam alterações nos princípios produtivos.

Para melhor compreender a definição acima estabelecida, quanto aos modelos produtivos e suas componentes, apresentaremos a configuração da trajectória do 
modelo fordista do pós-segunda guerra mundial em França. Devemos, neste quadro, entender o fordismo como sendo um sistema produtivo de acumulação intensiva que, fruto de um compromisso salarial institucionalizado, favorece o surgimento de importantes ganhos de produtividade, dos quais uma grande parte é distribuída aos assalariados. $\mathrm{O}$ fordismo baseia-se num círculo virtuoso entre o sistema produtivo e consumo. Enquanto sistema social (organização produtiva, compromisso salarial, regulação pelo Estado das políticas monetárias, fiscal, comercial, etc..), aquele não pode ser dissociado das técnicas que aceita e, a partir das quais, ele se desenvolve, para além de que assenta sobre um compromisso salarial onde as duas esferas indissociáveis do capitalismo (o consumo e a produção), que se conciliam graças a existências de técnicas que funcionam nas duas esferas em simultâneo. Esta é apenas a condição para a acumulação. Assim sendo, o fordismo não é mais do que uma combinação particular e economicamente virtuosa de uma organização social (produtiva e de consumo) e de técnicas (o motor de explosão e a electricidade) (Durand, 1993a: 126).

A história económica francesa do pós-guerra retrata esta integração generalizada e conseguida dos assalariados nos modos de produção. Assiste-se a uma penetração acelerada das estruturas capitalistas de organização e gestão da produção na comercialização dos bens de consumo, o que não deixa de alterar a natureza das relações entre produção e consumo. Um dos objectivos do modo de produção fordista era reduzir, por meio da racionalização, os tempos de execução, fruto de uma avançada mecanização. Pretendia-se aumentar a produtividade do factor trabalho e gerir o tempo e processo de execução. Acima de tudo, procurava-se o melhor gesto. Enquanto princípio geral de organização do trabalho, o fordismo que, segundo Alain Lipietz (1996: 7), não é mais do que o taylorismo mais a mecanização, já tinha emergido, mas de uma forma difusa, dispersa e pouco coerente no modo de regulação anterior - modo de regulação concorrencial que vigorou de meados do Século XIX até 1945. Estes princípios fordistas já estavam disseminados em numerosas actividades industriais, essencialmente indústrias intermédias e de consumo. Apesar de tudo, esses mesmos princípios não puderam desenvolver-se sem provocar perigosos desequilíbrios, a não ser que fossem reunidas as condições de uma transformação importante do tipo de consumo da maioria da população, incluindo os assalariados (Bertrand, 1984: 70). A reorientação sectorial dos investimentos em França, fundamentalmente direccionada para o sector dos bens de equipamento e o uso acrescido de novas técnicas de índole capitalista, provocaram alterações significativas nas formas de organização do trabalho, ideia essa corroborada pelas estatísticas ao descreverem, nos trinta gloriosos anos, a extensão do trabalho em cadeia e, consequentemente, a aplicação dos princípios fordistas de organização do trabalho (cf: Boyer, 1978: 21,22). Aliás, os primeiros vestígios de produção em massa em França remontam ao final da primeira Guerra Mundial '. Apesar de ser impossível uma análise detalhada, 
o mesmo autor acha ser bastante provável que os movimentos de concentração ocorridos nos anos cinquenta, com particular ênfase nos anos sessenta após a adesão à Comunidade Económica Europeia, exerceram efeitos significativos sobre a extensão da produção em série em diferentes sectores, com particular destaque para o sector dos bens intermédios.

No âmbito da planificação estatal, o IV Plano, e essencialmente o V Plano elaborados pelo Estado em 1965 para o período de 1966-1970 - incidiam sobre a competitividade da indústria francesa. Estes planos marcam uma nova aproximação à realidade macroeconómica, e assentam sobre uma distinção clara entre os sectores ditos protegidos (os sectores que se encontram relativamente ao abrigo da concorrência internacional, e que estão em condições de fixar o preço que lhes permita libertar meios para autofinanciar os seus investimentos) e os sectores expostos (os sectores que enfrentam directamente a concorrência estrangeira, e que acabam por se adaptar aos preços determinados pelo mercado externo). $\mathrm{O}$ futuro da economia francesa basear-se-ia nos ditos sectores expostos. A principal ideia é que somente grupos de dimensão internacional seriam capazes de investir, inovar e investigar com vista a uma bem sucedida penetração no mercado internacional. Para além disso, as disposições jurídicas e fiscais adoptadas, essencialmente em 1965 e em 1967, visaram claramente eliminar os obstáculos à concentração (Asselain, 1984: 112). Ao debruçarmo-nos sobre o sector automóvel, sector esse que está por muitos intimamente relacionado com o fordismo, constatamos que, após a II grande guerra, desaparece a maioria dos pequenos construtores de veículos ${ }^{2}$. O sector passa a ser dominado por três grandes construtores: Renault, Citröen e Peugeot, representando mais de dois terços da produção. $O$ resto do mercado era dividido entre o pequeno construtor Panhard, que sobrevive apesar das dificuldades, e as filiais da Ford e da Fiat (Simca) (Brémont, 1984: 20).

Desta forma, a associação entre os métodos tayloristas/fordistas e o acesso ao consumo de massa por parte dos assalariados deu-se, em França, a partir da segunda metade do Século XX. Relembrando Robert Boyer, no seu primeiro trabalho, "ensaio sobre o capitalismo de Estado francês, a partir da década de cinquenta "productivité et salaire enregistrent bientôt une croissance rapide et régulière, qui témoigne du passage à un nouveau mode de croissance" (1996: 106). De facto um crescimento forte e regular, para além de uma boa previsibilidade da evolução das normas de consumo, tornava relativamente eficazes a centralização e o controlo hierárquico no seio das empresas. Não obstante, o modelo fordista pressupõe igualmente uma forte centralização das decisões e do tratamento da informação, de acordo com um processo que justapõe uma série de divisões, ocupando-se respectivamente da concepção, da produção, da gestão de pessoal e financeira, entre outras. Esta é outra das características do fordismo: a estreita separação entre a concepção, organização do processo de produção e a execução das tarefas estandardizadas e formalmente prescritas. Por analogia, desenvolve-se 
uma série de hierarquias que procuram assegurar o controlo das unidades de nível hierárquico inferior.

Por outro lado, e de acordo com Boyer (1993a: 35), outro princípio consistia em organizar "une stricte hiérarchie entre la conception, puis l'organisation de la production, enfim la vente, selon un principe de pilotage par l'amont". Tal objectivo visava que os bens, produzidos em série e a baixos custos, tivessem sempre garantido o seu escoamento, apesar da sua qualidade, por vezes, ser bastante medíocre. $\mathrm{O}$ marketing e a publicidade acabavam por recorrer exclusivamente a técnica do "push", ao pretender "impingir"o produto ao consumidor e garantir o escoamento do mesmo. Assim sendo, a baixa relativa dos preços visava fomentar e desenvolver o consumo em massa. As grandes empresas, desta forma, reservavam-se à parte estável da procura, enquanto todo um conjunto de pequenos produtores subcontratados asseguravam a satisfação da procura de bens diferenciados de pequena série e possibilitavam uma resposta rápida em situações de mudança da conjuntura ${ }^{3}$. Este mesmo autor reconhece (1978: 18) que em França, apesar do crescimento global da procura, não ocorreu qualquer aceleração substancial após 1968 e, apesar do crescimento rápido do estoque de capital produtivo, as denominadas "enquêtes de conjoncture" revelam uma insuficiência duradoura dos equipamentos instalados para satisfazer a procura do mercado.

Contudo, não podemos menosprezar a importância das relações salariais associadas a esta fase. Em numerosos países, fortes conflitos de trabalho permitem o estabelecimento, em regra, de compromissos salariais. O compromisso salarial fordista associa a aceitação da racionalização, da mecanização e institucionalização de uma fórmula salarial garantindo, em troca, uma progressão do nível de vida mais ou menos em linha com a dinâmica da produtividade (Boyer, 1993a: 37). Daí se compreende que os conflitos dos anos sessenta e setenta apenas culminassem em aumentos salariais, com vista à obtenção de compensações financeiras pelo trabalho repetitivo, monótono, mas raramente para a obtenção de uma maior humanização do trabalho do pós-guerra. A classe operária francesa denota ter saído reforçada. Após duros e violentos movimentos, estes desenvolveram práticas reformistas, visando a melhoria da distribuição dos ganhos em favor dos trabalhadores, passando a ser igualmente regra os salários serem indexados ao nível geral de preço. Em contrapartida, o Patronato sai da guerra pouco engrandecido, ao ter que aceitar impavidamente as nacionalizações de 1945/46 (EDF; GDF, Renault; Bancos e Seguros), a reforma nas empresas e inúmeras medidas de protecção familiar e social. Contudo, o Patronato não deixou de beneficiar da queda, entre 1945 e 1950, dos salários reais, enquanto a retoma da produção já se tinha iniciado. Assim sendo, os lucros aumentaram e permitiram um importante autofinanciamento para a necessária modernização da estrutura empresarial (Barou, 1984: 89). 
Indubitavelmente a especificidade do modelo francês está associada ao facto do Estado Providência se ter tornado uma realidade institucionalizada e se ter assumido como principal mecanismo de coordenação. O Estado passou a estar no centro do estabelecimento de formas institucionais no domínio do trabalho, da concorrência e da inserção internacional. No âmbito da relação salarial, destaca-se o papel da lei de 1950 , relativa à extensão das convenções colectivas e a partilha dos frutos do crescimento. A intervenção do Estado visou estender as conquistas dos trabalhadores de uma empresa ao conjunto das empresas que compunham o sector. As "Ordennances", ao criarem a Segurança Social, e as inúmeras medidas sociais de assistência, de indemnização (desemprego) e de redistribuição (prestações familiares, salário mínimo, etc.), organizaram e centralizaram a protecção social, permitindo que os custos de reprodução dos assalariados fossem um encargo colectivo e que o elo, entre empresa e assalariado, fosse progressivamente distendido e substituído por um sistema global (Bertrand, 1986: 79).

Em síntese, o modelo fordista manifestava uma coerência forte e dinâmica, porque permitia conter conflitos, por vezes violentos, e convertê-los em elementos estabilizadores do modo de regulação em vigor. Para além disso, o fordismo sempre manifestou grandes capacidades para se inserir em práticas e tradições nacionais variadas. Diversos trabalhos sugeriram que os grandes países da OCDE conseguiram desenvolver a sua própria variante, sendo uma delas, o fordismo, impulsionado pelo Estado em França (cf. Boyer, 1993a: 37).

\section{O MODELO PÓS-FORDISTA: RUPTURA OU ACOMODAÇÃO AO FOR- DISMO}

É próprio das economias industrializadas exercer uma pressão ao nível da inovação, suscitar também uma sucessão de crises económicas, para além de uma extensão do espaço geográfico do mercado e uma internacionalização da produção. Estas tendências conduziram do sucesso ao esgotamento progressivo do potencial de expansão do modelo produtivo, mas também do modelo de regulação em vigor. Enquanto modo de regulação, e segundo o seu trabalho sobre o Capitalismo de Estado Francês, a crise do regime fordista, segundo Benjamin Coriat (1995: 389), começa no âmbito do Sistema Monetário Internacional, isto é, com a declaração unilateral de suspensão da convertibilidade do dólar em ouro, o que implicava o abandono do sistema de câmbios fixos e a entrada num sistema de câmbios flutuantes. Tal facto privou o recurso à estratégia de crescimento via desvalorização do franco. Em seguida, a crise de 73 põe fim à disponibilidade quase ilimitada de energia a baixo custo, o que não deixa de atingir um dos pilares do crescimento francês, visto que este país importava grande parte da energia. 
Entre outros aspectos, e neste contexto, salienta-se igualmente a onda de desregulamentações nos grandes serviços internacionais (transportes aéreos, telecomunicações), mas essencialmente nos serviços financeiros que acabam por transformar o contexto de actividade das empresas. A economia francesa demonstrou uma clara inadaptação às épocas de crise e de depressão, contribuindo para a deterioração da "performance" comercial face às outras economias. Assim sendo, a crise do modelo não é meramente acidental, ou temporária, mas demonstra possuir um carácter durável e estrutural, visto que a própria lógica do modo de regulação se encontra desestabilizada e pouco coerente (Boyer, 1993a: 38). Em nossos dias, existe um certo conformismo quanto ao novo paradigma produtivo que emerge após a crise das últimas três décadas: o novo tipo de empresa deve ser comunicante, polivalente, inovadora, organizada em redes, vendendo num mercado internacional produtos de alta qualidade e de elevado valor acrescentado, e garantindo, por fim, elevados salários e estabilidade de emprego. Todavia, a aplicação do novo paradigma ultrapassa largamente as indústrias de montagem, passando a sua aplicação a ser também possível em diversos sectores, entre os quais os serviços. Convém relembrar que este processo de emergência é extremamente lento, porque implica reestruturações intensivas e alterações dos pólos regionais de desenvolvimento. A superioridade do novo e alternativo modelo produtivo, quer ele seja o toyotismo ou o udvalismo, reside em grande parte na nova dinâmica macroeconómica. Deve-se à grande incerteza quanto à evolução das taxas de juro e de câmbio, para além das perspectivas de crescimento e o endurecimento da concorrência internacional, o que torna tão eficazes os princípios da inovação permanente, da polivalência, mas também o desinteresse dos assalariados pelos objectivos globais da empresa (Boyer, 1993b: 35). Tradicionalmente, enquanto modo de regulação, o modelo fordista, que pressupõe poderosas e importantes intervenções do Estado, moderniza-se com maior facilidade em períodos de regime internacional estável e não em períodos de crise, em consequência dos compromissos institucionais e dos custos que ela provoca.

Poderá parecer algo simplicador apresentar o passado como um mundo onde a competição pelos custos reinava (com as consequentes economias de escala, e níveis de produtividade-volume). Mas o novo facto indesmentível é, com o acréscimo vertiginoso e de intensidade da concorrência, com a imprevisibilidade crescente que resulta do enfraquecimento geral dos mecanismos de estabilização dos mercados, o lugar que ocupam os novos modos de concorrência:

- por diferenciação;

- pela qualidade;

- pela variedade;

- pelo tempo, que se baseia numa redução do tempo de entrega e redução dos ciclos de desenvolvimento;

- pela inovação. 
Neste quadro renovado, se desenvolve um novo discurso acerca do "management" e do modo de organização das empresas. Este novo discurso deixou de incidir, como nos anos sessenta e setenta, sobre as necessárias correcções sociais à organização do trabalho, sendo esta última rejeitada pelos trabalhadores e deslocada, face aos níveis de escolarização e aos modos de vida. Este novo discurso passa a recair sobre as novas condições técnicas e económicas. Os princípios-chave deste novo "management" começam já a ser conhecidos, e podem ser resumidamente retratados como sendo:

- Integração, inicialmente, e aproximação sistémica dos ciclos de produção: em particular, a necessidade de se passar de uma integração baseada sobre o recurso trabalho a uma gestão mais global dos recursos, resultado da elevada assimetria que se tinha progressivamente instalado entre a utilização óptima da mão-de-obra e a incrível subutilização das máquinas e das matérias-primas num contexto de recessão. Mas, igualmente, à investigação de acoplagem entre as diversas fases do ciclo produtivo, o desenvolvimento, fabrico e comercialização - a qualidade desta acoplagem é tão importante, ou mais, que a eficácia própria de cada uma das funções. A integração deve visar o estabelecimento de laços mais estreitos com os clientes, para absorver as novas procuras e as críticas, para além de permitir uma redução de custos.

- Horizontalidade dos procedimentos e das comunicações: necessidade de encurtar a cadeia da comunicação para se ser mais rápido e mais reactivo.

- Descentralização das estruturas e das decisões: necessidade de tornar as decisões mais eficazes, reaproximando-as do local de definição dos problemas e execução das actividades; mas também vontade de reencontrar, pela competitividade entre unidades descentralizadas, um motor da acção e inovação algo enfraquecido nas grandes estruturas burocráticas tradicionais (Veltz, 1993: 149).

- Acréscimo das qualificações e mobilização dos assalariados. As tecnologias, e as organizações, cada vez mais complexas, mas também as restrições de qualidade exigem nos assalariados conhecimentos técnicos e uma compreensão global e maior dos sistemas produtivos. Os assalariados, incluindo os executantes, devem ser mobilizados para os objectivos fixados pelas direcções das empresas. Os resultados não podem ser obtidos pela simples coerção como era o caso no fordismo clássico. O envolvimento dos assalariados só pode ser voluntário e compete às direcções criarem as condições para este envolvimento, a partir dos ganhos obtidos pelo novo modelo produtivo.

Contudo, podem coexistir tensões entre o objectivo de integração, isto é, a investigação de organizações, e o objectivo de descentralização. Apesar de tudo, 
é a construção dos compromissos entre estes princípios que domina hoje as grandes escolhas da arquitectura dos sistemas produtivos. As características do novo modelo produtivo são aqui apresentadas de uma forma genérica, mas aquelas devem ser adaptadas e moldadas às formas nacionais e históricas próprias de cada um dos países industrializados (Durand, 1993: 130,131).

A França comprova ter enormes dificuldades em progredir rumo aos novos princípios. Segundo Boyer (1993a: 71) é, por exemplo, significativo que, tanto em termos de princípio como de organização, este país denote estar ainda a uma grande distância do novo paradigma produtivo. As empresas francesas sempre demonstraram ser bons alunos na assimilação dos métodos americanos, e foi extremamente penoso estas tomarem consciência dos limites de um modelo que lhes tinha possibilitado um desenvolvimento sem precedente. Daí se compreende que, entre os países da Europa, este foi o último país a tomar consciência da ruptura da dinâmica fordista à escala internacional, e da crescente ineficácia dos conceitos fordistas. Por exemplo, em França, as tecnologias de informação foram raramente utilizadas com vista à descentralização, melhor repartição das responsabilidades e aumento da qualificação dos assalariados. Bem pelo contrário, esta nova geração de inovações permitiu apenas a consolidação do equivalente a um neofordismo: conceber equipamentos sofisticados para um melhor controlo dos trabalhadores. Assim sendo, Jean-Pierre Durand, bem como Michel Freyssenet, presumem que o neofordismo esteja mais na ordem do dia do que o pós-fordismo (Boyer, 1993a: 78,79). Por sua vez, Durand (1993: 139) afirma mesmo que, em França, “ les transformations actuelles (polyvalence, élargissement des taches, communication horizontale...) correspondent plus à un aménagement de l'ancien système qu'à l'accouchement d'un nouveau modèle productif'. Esta inércia explica-se por inúmeros traços específicos da economia e da sociedade francesas.

\section{CONCLUSÃO}

O papel preponderante do Estado no processo de industrialização torna difícil, a priori, a inserção numa produção diferenciada, orientada para a satisfação dos consumidores. A força da indústria francesa reside ainda nos sectores alimentados pelo mando público (telecomunicações, centrais nucleares, armamento...). Para além disso, as relações conflituosas de trabalho e o enfoque sobre os salários como primeiro objectivo das reivindicações não favorecem o estabelecimento de contratos do tipo toyotista. Para além de que a forte dicotomia entre o sistema educativo geral e a formação profissional tende a privilegiar o saber, em vez do saber-fazer, estabelecendo um fosso quase intransponivel entre as carreiras dos O.S. (Ouvrier Spécialiser) e a dos quadros intermédios (Boyer, 1993a: 79). É exactamente pela existência de fronteiras fortemente estabelecidas que o novo 
paradigma produtivo, ao emergir, enfrenta dificuldades. Se, por ventura, é incontestável a melhoria da qualificação dos operários, a manutenção de uma divisão hierarquizada do trabalho mantem-se. Podemos, desta forma, demonstrar que, pelo menos, duas características do modelo taylorista tendem a perpetuar-se e a impedir o surgimento de um modo produtivo realmente pós-fordista. $\mathrm{O}$ primeiro deles é a manutenção da separação entre colarinhos azuis e brancos, e a procura constante da passagem da linha de montagem para o gabinete, fruto da desvalorização do trabalho manual. Por fim, a segunda característica é a dos limites existerites de progressão nas carreiras dos operários e a necessidade de abandonar a linha de montagem para obter melhores rendimentos. Por outro lado, há que contar com uma estruturação muito rígida e dividida das empresas, o que não deixa de travar a mobilidade dos assalariados: grupos sociais muito estruturados à volta de funções específicas (e centralizadas) levam ao fracasso as reformas estruturais. $\mathrm{O}$ elevado número de categorias profissionais produz fortes desigualdades e provoca desmotivação, ao nível do empenhamento dos assalariados. Palavras de ordem como "carriére ouvriére" (Valéry Giscard d'Estaing) ou de "réhabilitation du travail manuel' (Jean-Pierre Soisson, Martin Aubry) não devem apenas satisfazer os propósitos de homens da política mas, sim, das práticas de gestão se se decidir pela destaylorização e a aplicação de um novo modelo produtivo. Tal facto implica um enorme trabalho de imaginação, na empresa e fora dela (imagem da formação profissional, por exemplo), bem como um nivelamento dos rendimentos auferidos pelas diferentes categorias de assalariados (Durand, 1993: 140,141).

\section{NOTAS}

* Trabalho desenvolvido no âmbito do mestrado.

1 De acordo com Fridenson, " il a fallu que nos industriels fassent un effort considérable, en améliorant leur outillage. Dans le gros établissements, on peut voir, en effet, les machines-outils les plus récentes(...) à chaque instant sont introduites venant modifier, simplifier encore et toujours les systémes de fabrication (...) Cette simplication permet l'appel croissant à une main d' oeuvre non qualifiée ou semi qualifiée. (...) elle passe, chez Renault, de 5,1\% des effectifs à 29,6\% en 5 ans ( 1906-1911)" (Bremont, 1984: 10).

2 Em 1955, apenas permacem cinco pequenos construtores: Delahaye, Delage, Hotchkiss, Rovin, Salmson.

${ }^{3}$ De acordo com Fridenson, nos anos cinquenta "Renault e Citröen attaquent le marché par ses deux extrémités ( $4 C V$, puis Dauphine d'un côté, Frégate de l'autre pour Renault; 2 CV d'un côté, Traction puis DS 19 de l'autre pour Citröen), que Peugeot partique la monoculture en s'attaquant au sommet de la gamme moyenne (203, puis 403)" (Bremont, 1984: 21). 


\section{BIBLIOGRAFIA}

ASSELAIN, Jean-Charles (1984), Histoire Économique de la France-du XVIII siècle à nos jours, vol. II, Paris, Édition du Seuil.

BAROU, Yves e KEIZER, Bernard (1985), Les Grandes Economies - États-Unis, Japon, Allemagne Fédérale, France, Royaume-Uni, Italie, Paris, Édition du Seuil.

BRÉMONT, Janine e SALORT, Marie-Martine (1984), L'industrie automobile: L'ere fordiste; La compétition entre nations; L'entrée de la robotique; Les entreprises françaises, qu'elle estratégie? , Paris, Hatier.

BERTRAND, Hugues (1986), "France: modernisations et piétinements", in Capitalismes en fin de siècle, Paris, Presses Universitaires de France.

BOYER, Robert (1978), “Accumulation, inflation, crises”, Paris, $2^{\mathrm{a}}$ Edição, Presses Universitaires de France.

BOYER, Robert (1993a), "Comment émerge un nouveau systéme productif ?", in Vers un nouveau modéle productif? ?, Paris, Syros, p. 33 - 89.

BOER, Robert (1993b), “ L'Aprés-fordisme ”, Paris, Syros.

BOYER, Robert (1994 a), "Les capitalismes vers le XXI ${ }^{\text {ème }}$ Siécle. Des transformations majeurs en quête de théories (I)", Notas Económicas - Revista da Faculdade de Economia da Universidade de Coimbra, $\mathrm{n}^{\circ} 3$.

BOYER, Robert (1994 b), "Les capitalismes vers le XXI ${ }^{\mathrm{ème}}$ Siécle. Des transformations majeurs en quête de théories (II)", Notas Económicas - Revista da Faculdade de Economia da Universidade de Coimbra, $\mathrm{n}^{\circ} 4$.

BOYER, Robert (1995), “Aux origines de la théorie de la Régulation”, in Théorie de la régulation - L'état des savoirs, Paris, La Découverte, pp. $21-30$.

BOYER, Robert (1996), "Le Capitalisme Étatique à la Française à la croisée des chemins", in Les Capitalismes en Europe, Paris, La Découverte, p 97 - 138

CORIAT, Benjamin (1995), "France: un Fordisme brisé... et sans successeur", in Théorie de la régulation - L'état des savoirs, Paris, La Découverte, p. 389 - 397.

COURLET, Claude e PECQUER, Bernard (1994), "Os Sistemas Industriais Locais em França", in As Regiões Ganhadoras - Distritos e redes: os novos paradigmas da geografia económica, Oeiras, Celta Editora, p $49-62$.

DURAND, Jean Pierre (1993a), "Le vrai-faux changement dans l'entreprise française?", in Vers un nouveau modéle productif?, Paris, Syros, p. 126 - 141.

VELTZ, Pierre (1993a), "Déstabilisation et résistance du taylorisme", in Vers un nouveau modéle productif?, Paris, Syros, p. $144-161$. 